\title{
KEPUASAN MASYARAKAT DI TINJAU DARIKUALITAS PELAYANAN YANG ADA PADA KANTOR DESA CITAYAM
}

\author{
Nurmin Arianto ${ }^{1}$, Afrido Adam Muhfany ${ }^{2}$ \\ ${ }^{1-2}$ Program Studi Manajemen Fakultas Ekonomi, Universitas Pamulang \\ E-mail: dosen01118@unpam.ac.id
}

\begin{abstract}
Penelitian ini bertujuan untuk mengetahui pengaruh kualitas pelayanan terhadap kepuasan masyarakat Desa Citayam.

Penelitian ini menggunakan metode analisis deskriptif kuantitatif dengan teknik pengambilan data menggunakan angket. Teknik sampling yang digunakan adalah menggunakan rumus slovin dengan sampel sebanyak 99 responden.

Analisis data menggunakan uji validitas, uji reliabilitas, uji asumsi klasik, analisis regresi, analisis koefisien korelasi, analisis koefisien determinasi dan uji hipotesis dan uji hipotesis menggunakan program IBM SPSS versi 25 .

Hasil penelitian ini menunjukan bahwa secara parsial kualitas pelayanan berpengaruh positif dan signifikan terhadap kepuasan masyarakat, dibuktikan dengan hasil perhitungan nilai $t$ hitung $>t$ tabel dengan nilai sebesar $13.469>1.98498$ dengan taraf signifikansi sebesar $0,000<0,05$ dengan demikian Ha1 diterima.
\end{abstract}

Keywords : Kualitas Pelayanan; Kepuasan

\section{ABSTRACT}

This study aims to determine the effect of service quality on community satisfaction in Citayam Village. This study used a quantitative descriptive analysis method with data collection techniques using a questionnaire. The sampling technique used was the Slovin formula with a sample of 99 respondents.

Data analysis used validity test, reliability test, classic assumption test, regression analysis, correlation coefficient analysis, determination coefficient analysis and hypothesis testing and hypothesis testing using the IBM SPSS version 25 program.

The results of this study indicate that partially service quality has a positive and significant effect on community satisfaction, evidenced by the results of the calculation of the value $t$ count $>t$ table with a value of 13,469> 1.98498 with a significance level of 0.000 $<0.05$, thus Hal accepted.

Keywords : Service Quality, Satisfaction

\section{PENDAHULUAN}

Sebagai salah satu indikator penyelenggaraan pemerintahan yang baik, penyelenggaraan pelayanan kepada masyarakat merupakan salah satu tanggung jawab dan fungsi pemerintah untuk mencapai kesejahteraan. Pelayanan merupakan salah satu tugas penting yang tidak dapat diabaikan oleh pemerintah daerah. Jika terjadi masalah di sektor jasa, hampir dapat dipastikan semua sektor akan berdampak pada kemacetan lalu lintas. Oleh karena itu, sesuai dengan kewenangan yang diberikan oleh pemerintah pusat kepada pemerintah daerah, perlu adanya perencanaan yang baik kepada masyarakat bahkan penetapan standar pelayanan. Perkembangan, penyelenggaraan pemerintahan dan pelayanan publik semakin meningkat dari tahun ke tahun, hal ini sejalan dengan meningkatnya dukungan untuk memberikan pelayanan yang lebih cepat, tepat dan tepat. Oleh karena itu, peningkatan layanan kantor pedesaan harus terus dilakukan. Salah satu tugas kepala desa 
adalah memahami tuntutan masyarakat, harus mampu merumuskan pedoman untuk menjawab tuntutan tersebut dengan tepat agar segala tindakan datang dari pimpinan tertinggi dan tuntutan pemerintah. masyarakat.

Pelayanan merupakan peran utama lembaga sebagai pegawai negeri dan abdi masyarakat yang memberikan pelayanan publik kepada masyarakat. Pelayanan publik yang berkualitas yang dapat memenuhi kebutuhan masyarakat menjadi tanggung jawab pemerintah. Kualitas pelayanan publik menjadi tolak ukur. Kegiatan nasional. Peran pemerintah dan kelembagaannya sebagai pelayanan publik (PNS) merupakan salah satu syarat reformasi. Standar layanan merupakan tolok ukur yang dapat digunakan sebagai pedoman dalam penyediaan layanan, dan juga dapat digunakan sebagai acuan untuk menilai kualitas layanan (sebagai janji dan janji). Dilakukan oleh penyedia layanan publik dalam lingkup layanan yang berkualitas tinggi, cepat, sederhana, dan terjangkau.

Menurut Peraturan Menteri Pendayagunaan Aparatur Negara Dan Reformasi Birokrasi Republik Indonesia Nomor 15 Tahun 2014, komponen standar pelayanan yang terkait dengan proses penyampaian pelayanan meliputi Persyaratan, prosedur, jangka waktu pelayanan, biaya/tarif, produk pelayanan, dan penanganan pengaduan.

Buruknya kualitas pelayanan publik yang diberikan oleh pegawai negeri telah memperburuk citra sosial pemerintah. Beberapa orang yang menghadapi pita merah selalu mengeluh dan merasa frustrasi dengan layanan yang mereka berikan. Sebagian orang masih meremehkan efektivitas birokrasi. Pelayanan yang diberikan kepada masyarakat umum yang tidak puas dengan masyarakat. Karena berbagai alasan yang tidak dapat diterima masyarakat, maka pelayanan yang diberikan terlalu rumit. Akibatnya, layanan yang diberikan seringkali tidak efektif dan efisien. Situasi ini menimbulkan ketidakpuasan masyarakat terhadap penggunaan layanan publik. Semua ini membuat gereja enggan mengurus apapun. Rdiri Lura, sekretaris jalan, departemen dan jabatan fungsional. Bagian Kelurakhan mencakup bagian tentang pemerintahan, urusan dan ketertiban umum, bagian tentang bisnis dan pembangunan, dan bagian tentang kesejahteraan dan pemberdayaan komunitas yang terdiri dari 11.806 orang (Wikipedia).com dan https://bogorkab.bps.go.id/publication/) Peringkat layanan Desa Citayam didasarkan pada kepuasan masyarakat. Peringkat komunitas memberikan indikator untuk mengukur efektivitas pelayanan publik. Dalam hal kepuasan masyarakat, berikut hasil evaluasi atas pelayanan yang diberikan masyarakat:

\section{Tabel 1.1}

Penilian Kualitas Pelayanan di Kantor Desa Citayam

\begin{tabular}{|c|c|c|c|}
\hline No. & Pernyataan & $\mathbf{S}$ & RR \\
\hline \multicolumn{4}{|c|}{ Sikap Pegawai Kelurahan } \\
\hline 1 . & $\begin{array}{l}\text { Pegawai Kantor Desa Citayam bersikap } \\
\text { ramah kepada saya. }\end{array}$ & $\begin{array}{l}14 / 30 * 100 \% \\
=47 \%\end{array}$ & $\begin{array}{l}16 / 30 * 100 \% \\
=53 \%\end{array}$ \\
\hline \multicolumn{4}{|c|}{ Perhatian } \\
\hline 2. & $\begin{array}{l}\text { Pegavai Kantor Desa Citayam } \\
\text { memberikan pelayanan secara maksimal } \\
\text { kepada saya. }\end{array}$ & $\begin{array}{l}11 / 30 * 100 \% \\
=37 \%\end{array}$ & $\begin{array}{l}19 / 30 * 100 \% \\
=63 \%\end{array}$ \\
\hline \multicolumn{4}{|c|}{ Tindakan } \\
\hline 3. & $\begin{array}{l}\text { Kantor Desa Citayam tanggap dalam } \\
\text { menghadapi masalah yang timbul. }\end{array}$ & $\begin{array}{l}14 / 30 * 100 \% \\
=47 \%\end{array}$ & $\begin{array}{l}16 / 30 * 100 \% \\
=53 \%\end{array}$ \\
\hline \multicolumn{4}{|c|}{ Kemampuan } \\
\hline 4. & $\begin{array}{l}\text { Gedung yang dimiliki Kantor Desa } \\
\text { Citayam memadai. }\end{array}$ & $\begin{array}{l}13 / 30 * 100 \% \\
=43 \%\end{array}$ & $\begin{array}{l}17 / 30 * 100 \% \\
=57 \%\end{array}$ \\
\hline \multicolumn{4}{|c|}{ Penampilan } \\
\hline 5. & $\begin{array}{l}\text { Kantor Desa Citayam menjaga kerapihan } \\
\text { penampilan Pegawai. }\end{array}$ & $\begin{array}{l}12 / 30 * 100 \% \\
=40 \%\end{array}$ & $\begin{array}{l}18 / 30 * 100 \% \\
=60 \%\end{array}$ \\
\hline
\end{tabular}

Sumber data Prasurvey, 2021

Berdasarkan data sebelum penulis melakukan survei terhadap 30 warga Kelurahan, hasil penelitian menunjukkan bahwa banyak warga yang meragukan pelayanan aparat desa Bedahan Proporsi desa tertinggi adalah 63\% warga. Masyarakat desa yang memberikan pelayanan secara menyeluruh artinya masih ada masyarakat yang 
skeptis terhadap pelayanan yang diberikan, hal ini terlihat dari hasil observasi awal. Banyak warga yang masih mengeluhkan proses pemberian ktp elektronik dan pengelolaannya yang membingungkan. "Hal ini menunjukkan bahwa kualitas pelayanan yang diberikan oleh aparat kelurahan masih buruk dan mereka kurang puas dengan pelayanan yang diberikan oleh banyak warga, peran pemerintah dalam hukum". (UU). Pasal 1 Undang-Undang Nomor 25 Tahun 2009 tentang Pelayanan Publik mengatur: "Pelayanan publik mengacu pada kegiatan atau serangkaian tindakan yang diberikan kepada setiap warga negara dan penduduk barang, jasa dan / atau pengelolaan administrasi sesuai dengan peraturan perundang-undangan untuk memenuhi kebutuhan pelayanan. Layanan tersebut harus mencakup layanan yang disediakan oleh penyedia layanan nasional ". Oleh karena itu, sebaiknya Kantor Desa Citayam tidak hanya dapat memberikan layanan masyarakat yang datang ke kantor desa, tetapi juga survei awal kepuasan masyarakat yang ditunjukkan pada tabel berikut:

Tabel 1.2

Penlian Kepuasan Masyarakat di Kantor Desa Citayam

\begin{tabular}{|c|c|c|c|}
\hline \multicolumn{2}{|c|}{ No. Pernyataan } & $\mathbf{S}$ & RR \\
\hline \multicolumn{4}{|c|}{ Kesesuaian Harapan } \\
\hline 6. & $\begin{array}{l}\text { Pelayanan yang diberikan Kantor Desa Citayam } \\
\text { cepat serta tepat sesuai dengan permintaan saya. }\end{array}$ & $\begin{array}{l}12 / 30 * 100 \% \\
\quad=40 \%\end{array}$ & $\begin{array}{l}18 / 30 * 100 \% \\
\quad=60 \%\end{array}$ \\
\hline \multicolumn{4}{|c|}{ Persepsi Kinerja } \\
\hline 7. & $\begin{array}{l}\text { Kinerja pegawai pelayanan di Kantor Desa } \\
\text { Citayam sangat baik. }\end{array}$ & $\begin{array}{l}13 / 30 * 100 \% \\
=43 \%\end{array}$ & $\begin{array}{l}17 / 30 * 100 \% \\
\quad=56 \%\end{array}$ \\
\hline \multicolumn{4}{|c|}{ Penilaian Pelanggan } \\
\hline 8. & $\begin{array}{l}\text { Pegawai Kantor Desa Citayam menerapkan } 3 \mathrm{~S} \\
\text { (Senyum, Sapa, Salam). }\end{array}$ & $\begin{array}{l}11 / 30 * 100 \% \\
\quad=36 \%\end{array}$ & $\begin{array}{l}19 / 30 * 100 \% \\
\quad=64 \%\end{array}$ \\
\hline
\end{tabular}

Sumber data Prasurvey, 2020.

Dari data kepuasan masyarakat ternyata masih terdapat keraguan terhadap pelayanan yang diberikan pegawai dimana masih terlihat skor tinggi yaitu sebesar $64 \%$ dimana masih ada pegawai yang tidak menerapkan $3 \mathrm{~S}$ pada saat melayani masyarakat yang datang ke kelurahan, hal ini cukup membuktikan bahwa masih terdapat masyarakat yang kurang puas terhadap pelayanan yang di berikan oleh pegawai karena pada dasarnya kepuasan masyarakat merupakan Perasaan senang atau kecewa yang muncul setelah membandingkan kinerja (hasil) produk yang dipikirkan terhadap kinerja (atau hasil) yang diharapkan, Kotler (2014: 150), masyarakat disini membandingkan ekspektasi dengan kenyataan yang telah diterima. Menurut Tabel 1.2, banyak masyarakat yang terlihat masih kurang puas dengan pelayanan Kantor Desa Citayam, sehingga fenomena ini terjadi. Penulis berminat malakukan penelitian dengan tema "Kepuasan Masyarakat di tinjau dari kualitas pelayanan yang ada pada Kantor Desa Citayam".

\section{Rumusan dan Tujuan Penelitian:}

Tujuan penelitian berawal dari adanya rumusan masalah, maka dari itu yang menjadi rumusan msalah dalam penelitian ini adalah untuk mengetahui bagaimana kualitas pelayanan dan kepuasan kepuasan masyarakat pada Kantor Desa Citayam serta mengetahui bagaimana pengaruh kualitas pelayanan terhadap kepuasan masyarakat desa citayam 


\section{TINJAUAN TEORI \\ Kualitas Pelayanan}

Kualitas pelayanan merupakan upaya perusahaan untuk memenuhi kebutuhan pelanggan dan memperoleh kepuasannya. Salah satu nilai utama yang diharapkan pelanggan dari layanan adalah kualitas layanan yang tinggi. Kualitas layanan menggambarkan bagaimana perusahaan dan organisasi menyediakan produk yang memenuhi kebutuhan konsumen. Menurut Kotler dan Keller (2013: 214), layanan mengacu pada aktivitas, manfaat, atau layanan tidak berwujud yang diberikan oleh satu pihak kepada pihak lainnya. Jika berwujud atau berwujud, tidak akan mengarah pada pengalihan kepemilikan dan bukan produk . Zeithamal dan Bitner dalam Hurriyati (2014: 28) meyakini bahwa konsep jasa adalah suatu kegiatan ekonomi yang produksinya secara fisik berbeda dengan produk yang dikonsumsi dan diproduksi secara bersamaan, memberikan nilai tambah, dan pada prinsipnya tidak relevan. Menurut Hurriyati (2013: 16) kualitas pelayanan merupakan ukuran yang diambil untuk memenuhi kebutuhan orang lain (pelanggan, pelanggan, pelanggan, tamu, dll), dan kepuasan mereka tergantung pada objek yang dilayaninya. Dan orang-orang yang mereka layani. Menurut Kotler dan Keller (2012:119) terdapat lima indikator yang dapat digunakan untuk mengukur kualitas pelayanan, yaitu: Bukti Fisik (Tangible), Keandalan (Reliability), Daya Tangkap (Responsiveness), Jaminan (Assurance), Empati (Empathy)

\section{Kepuasan}

Masyarakat adalah konsumen utama layanan. Aparat pemerintah akan memberikan pelayanan terbaik untuk memuaskan masyarakat. Oleh karena itu, mengukur kepuasan masyarakat menjadi sangat penting karena memberikan informasi yang berguna bagi perkembangan instansi. Menurut Kotler dan Keller (2016: 138), "Kepuasan pelanggan adalah rasa senang atau kecewa seseorang, yang diperoleh dengan membandingkan karakteristik yang dirasakan (atau hasil) dari suatu produk dengan harapan yang diharapkan." Daryanto dan Setiabudi (2014: 43) menyatakan: "Kepuasan pelanggan adalah evaluasi emosional konsumen ketika mereka menggunakan suatu produk sekaligus memenuhi harapan dan kebutuhan konsumen yang menggunakan produk tersebut." Menurut Suyanto (2012: 35)), "Pelanggan kepuasan adalah tingkat perasaan seseorang setelah suatu perbandingan (prestasi atau prestasi). Akibatnya) perasaan itu bertentangan dengan harapan." Menurut Tjiptono (2011:453) ada konsep inti mengenai objek pengukuran, berikut indikator kepuasan konsumen (masyarakat) yaitu Kepuasan konsumen keseluruhan (overal customer satisfaction), Minat pembelian atau penggunaan ulang, Kesediaan untuk merekomendasi.

\section{Kerangka Pemikiran}

Sikap yang baik dapat menjelaskan hubungan teoritis antar variabel yang diteliti. Variabel dalam penelitian ini ada dua yaitu Kualitas Pelayanan (X) sebagai variabel bebas dan Kepuasan (Y) sebagai variabel terikat. Hubungan kedua variabel ini merupakan hubungan (linier) dimana X mempengaruhi Y. Dengan kata lain dapat dikatakan bahwa kualitas pelayanan yang baik mempengaruhi kepuasan. Dan didukung oleh penelitian terdahulu yaitu oleh Ni Made Ari (2015), Ludviyatus (2018) Alf (2017) yang menyatakan bahwa kualitas pelayanan memiliki pengaruh terhadap kepuasan. 


\begin{tabular}{|l|l|l|}
\hline \multicolumn{1}{|c|}{ Kualitas Pelayanan } & \multicolumn{1}{|c|}{ Kepuasan Masyarakat } \\
\hline Indikator: & \\
\hline - Bukti Fisik (Tangible) & - Keandalan (Reliability) \\
- Daya Tangkap & Indikator: \\
(Responsiveness) & - Kepuasan konsumen \\
- Jaminan (Assurance) & keseluruhan (Overal \\
- Empati (Empathy) & customer satisfaction) \\
Sumber: Kotler dan Keller & - Minat pembelian atau \\
(2012:119) & penggunaan ulang \\
& - Kesediaan untuk \\
& merekomendasi \\
\hline
\end{tabular}

\section{METODE PENELITIAN}

\section{Jenis Penelitian}

Penelitian yang kami lakukan bersifat kuantitatif dan bertujuan untuk membahas tantangan yang dihadapi Kantor Desa Citayam dalam hal kepuasan masyarakat terkait kualitas layanan. Data yang digunakan adalah data angka.

\section{Tempat dan Waktu Penelitian}

Yang menjadi objek penelitian ini adalah Kantor Desa Citayam yang bertempat di Jl. Raya Desa Citayam No. 154, Kp. Bulu RT 005/004, Desa Citayam, Kecamatan Tajurhalang, Kabupaten Bogor, Sedangkan waktu penelitian yang kami lakuka pada tahun 2021.

\section{Populasi dan Sampel}

Adapun populasi dalam penelitian ini di fokuskan kepada masyarakat Desa Citayam yang berusia $>17$ tahun atau yang telah memiliki KTP dikarenakan masyarakat yang menggunakan pelayanan Kantor Desa biasanya adalah mereka yang berusia $>17$ tahun. Adapun masyarakat Desa Citayam yang berusia 17 tahun ke atas yaitu sebanyak 6.910 orang. Sampel yang diperoleh yaitu sebanyak 99 responden hal ini diperoleh dengan menggunakan Slovin dengan tingkat erorr sebsar 10\% sedangkan teknik sampling yang digunakan yaitu Purposive Sampling dimana masyarakat yang berusia $>17$ th dan telah memiliki KTP dijadikan sebagai sample penelitian.

\section{Pengumpulan Data}

Didalam pengumpulan data kami menggunakan data primer yang terdiri dari Obervasi Partisipan dimana peneliti ikut terlibat didalam obeservasi karena peneliti bekerja juga di Kantor Desa tersebut dan Kuisioner yang kami gunakan ialah kuisoner tertutup dimana peneliti sudah menyediakan jawaban dengan menggunakan skala likert. Sedangkan data skunder yang di gunakan dengan refrensi berbagai jurnal penelitian dan buku yang ada di perpus serta internet.

\section{Teknik Analisis Data}

Didalam menganalisis data yang digunakan uji validitas dan uji reliablitas, uji asumsi klasik serta analisis regresi linier sederhana, uji korelasi, determinasi dan uji hipotesis (uji t).

\section{HASIL DAN PEMBAHASAN}

\section{Hasil Penelitian Deskriptif Karekteristik Responden}

Dari hasil survei gender terlihat bahwa 43,4\% responden berjenis kelamin laki-laki, dan $56,6 \%$ perempuan. Berdasarkan pekerjaan maka diketahui bahwa yang masih menjadi pelajar/mahasiswa sebanyak $11.1 \%$ responden, yang bekerja sebagai pegawai negeri sebanyak $8.1 \%$ responden, iang menjadi pengusaha dan pegawai swasta masing-masing 
$32.3 \%$ dan $34.35 \%$ responden, dan yang memiliki pekerjaan lainya sebanyak $14.15 \%$ responden. Jadi dapat diketahui bahwa responden dalam penelitian ini paling banyak adalah bekerja sebagai karyawan swasta, disusul dengan yang masih pengusaha, dan paling sedikit adalah bekerja sebagai pegawai negeri. Berdasarkan usia responden dimana responden terbanyak dalam penelitian ini adalah masyarakat berusia 20-29 tahun dengan jumlah 39.4\%, kemudian di susul responden berusia 30-39 tahun dengan jumlah $25.25 \%$, dan jumlah paling sedkit berusia $>50$ tahun dengan jumlah $5.05 \%$. Jadi kebanyakan masyarakat yang yang menggunakan pelayanan Desa adalah masyarakat yang berusia 20-39 tahun. jadi dapat disimpulkan bahwa pelayanan Desa untuk semua kalangan umur sesuai dengan keinginan dan kebutuhan dari masyarakat.

Dan dari pendidikan dilihat mayoritas pendidikan responden adalah SMA dimana diperoleh $62.6 \%$, kemudian pendidikan responden yang paling sedikit yaitu SD dan lainlain dengan masing masing responden sebanyak $6.1 \%$ dan $1 . \%$. jadi dapat disimpulkan pelayanan pada Desa Citayam tidak mengutamakan apa pendidikan masyarakat selama dapat melayani sesuai dengan keinginan dan kebutuhan dari masyarakat.

\section{Hasil Penelitian Deskriptif Variabel Penelitian}

\section{Variabel Kualitas Pelayanan}

Deskripsi Variabel Kualitas' Pelayanan (X)

\begin{tabular}{|c|c|c|c|c|c|c|c|c|}
\hline No & SS & S & RR & TS & STS & Total & Mean & Ket \\
\hline \multicolumn{8}{|c|}{ Bukti Fisik } \\
\hline 1 & 17 & 56 & 13 & 13 & 0 & 99 & 3.78 & B \\
\hline 2 & 10 & 47 & 24 & 15 & 3 & 99 & 3.46 & B \\
\hline \multicolumn{8}{|c|}{ Keandalan } \\
\hline 3 & 12 & 51 & 19 & 16 & 1 & 99 & 3.58 & B \\
\hline 4 & 9 & 47 & 27 & 16 & 0 & 99 & 3.49 & B \\
\hline \multicolumn{8}{|c|}{ Daya Tangkap } \\
\hline 5 & 17 & 43 & 26 & 13 & 0 & 99 & 3.65 & B \\
\hline 6 & 17 & 51 & 13 & 17 & 1 & 99 & 3.67 & B \\
\hline \multicolumn{7}{|c|}{ Jaminan } \\
\hline 7 & 15 & 47 & 24 & 13 & 0 & 99 & 3.65 & B \\
\hline 8 & 11 & 52 & 20 & 14 & 2 & 99 & 3.57 & B \\
\hline \multicolumn{8}{|c|}{ Empati } \\
\hline 9 & 11 & 44 & 28 & 16 & 0 & 99 & 3.51 & B \\
\hline 10 & 20 & 42 & 20 & 13 & 4 & 99 & 3.62 & B \\
\hline$\Sigma$ & 139 & 480 & 214 & 146 & 11 & 990 & \multirow{2}{*}{3.596} & B \\
\hline$(\%)$ & 14 & 48.5 & 21.6 & 14.7 & 1.11 & 100 & & \\
\hline
\end{tabular}

Sumber : Data primer yang telah di olah (2021)

Berdasarkan tabel diatas dapat dilihat bahwa kualitas pelayanan di Kantor Desa Citayam mendapat respon yang baik terlihat dari nilai rata-rata yaitu 3,595 yang berada pada rentang skala $(3,40-4,19)$. Dengan jumlah responden 99 orang dan dengan 10 pernyataan, yang menjawab "sangat setuju" sebanyak 139 atau 14\%, jawaban "setuju" sebanyak 5480 atau 48,5\%, jawaban "ragu-ragu" sebanyak 214 atau 21,6\%, jawaban "tidak setuju" sebanyak 164 atau 14,7\% dan jawaban "sangat tidak setuju" sebanyak 11 atau $1,11 \%$. 
Deskripsi Variabel Kepuasan Masyarakat (Y)

\begin{tabular}{|c|c|c|c|c|c|c|c|c|}
\hline No & SS & S & RR & TS & STS & Total & Mean & Ket \\
\hline \multicolumn{1}{|c|}{ Kepuasan Masyarakat Keseluruhan } \\
\hline 1 & 12 & 56 & 22 & 8 & 1 & 99 & 3.71 & B \\
\hline 2 & 7 & 54 & 22 & 16 & 0 & 99 & 3.53 & B \\
\hline \multicolumn{8}{|c|}{ Minat Pembelian atau PenggunaanUlang } \\
\hline 3 & 8 & 45 & 31 & 15 & 0 & 99 & 3.46 & B \\
\hline 4 & 4 & 41 & 35 & 17 & 2 & 99 & 3.28 & B \\
\hline \multicolumn{8}{|c|}{ Kesediaan untuk Merekomendasi } \\
\hline 5 & 4 & 38 & 36 & 18 & 3 & 99 & 3.22 & B \\
\hline 6 & 4 & 35 & 38 & 21 & 1 & 99 & 3.20 & CB \\
\hline$\sum$ & 39 & 269 & 184 & 95 & 7 & 594 & 3.40 & \multirow{2}{*}{ B }
\end{tabular}

Sumber : Data primer yang telah di olah (2021)

Berdasarkan tabel diatas dapat dilihat bahwa kepuasan masyarakat juga mendapat respon yang baik terlihat dari nilai rata-rata yaitu 3,40 yang berada pada rentang skala $(3,40-$ $4,19)$. Dengan jumlah responden 99 orang dan dengan 6 pernyataan, yang menjawab "sangat setuju" sebanyak 39 atau 6,57\%, jawaban "setuju" sebanyak 269 atau 45,3\%, jawaban "ragu-ragu" sebanyak 184 atau 31\%, jawaban "tidak setuju" sebanyak 95 atau $16 \%$ dan jawaban "sangat tidak setuju" sebanyak 7 atau 11,8\%.

Uji Instrument Penelitian Uji Validitas dan Reliabilitas

Rangkuman Hasil Uii Validitas Variabel Penelitian

\begin{tabular}{|c|c|c|c|c|}
\hline \multicolumn{5}{|c|}{ Kualitas Pelayanan (X) } \\
\hline No Kuisioner & R hitung & R tabel & Signifikansi & Keterangan \\
\hline 1 & 0,626 & 0,1663 & 0,000 & Valid \\
\hline 2 & 0,735 & 0,1663 & 0,000 & Valid \\
\hline 3 & 0,653 & 0,1663 & 0,000 & Valid \\
\hline 4 & 0,608 & 0,1663 & 0,000 & Valid \\
\hline 5 & 0,594 & 0,1663 & 0,000 & Valid \\
\hline 6 & 0,597 & 0,1663 & 0,000 & Valid \\
\hline 7 & 0,650 & 0,1663 & 0,000 & Valid \\
\hline 8 & 0,629 & 0,1663 & 0,000 & Valid \\
\hline 9 & 0,557 & 0,1663 & 0,000 & Valid \\
\hline 10 & 0,755 & 0,1663 & 0,000 & Valid \\
\hline \multicolumn{5}{|c|}{ Kepuasan Masyarakat (Y) } \\
\hline 1 & 0,703 & 0,1663 & 0,000 & Valid \\
\hline 2 & 0,696 & 0,1663 & 0,000 & Valid \\
\hline 3 & 0,728 & 0,1663 & 0,000 & Valid \\
\hline 4 & 0,721 & 0,1663 & 0,000 & Valid \\
\hline 5 & 0,715 & 0,1663 & 0,000 & Valid \\
\hline 6 & 0,663 & 0,1663 & 0,000 & Valid \\
\hline
\end{tabular}

Sumber : Output SPSS yang di olah (2021)

Rangkuman Hasil Uji Reliabilitas

\begin{tabular}{|c|c|c|c|c|}
\hline No & Variabel & $\begin{array}{c}\text { Alpha } \\
\text { Cronbacch }\end{array}$ & Syarat & Keterangan \\
\hline 1 & Kualitas Pelayanan (X) & 0,843 & 0,60 & Reliabel \\
\hline 3 & Kepuasan (Y) & 0,797 & 0,60 & Reliabel \\
\hline
\end{tabular}


Sumber: Output SPSS yang di olah (2021)

Dari tabel di atas dapat disimpulkan bahwa semua pernyataan dalam kuesioner dianggap reliabel dan layak digunakan dalam penelitian ini.

Uji Asumsi Klasik

Uji Normalitas

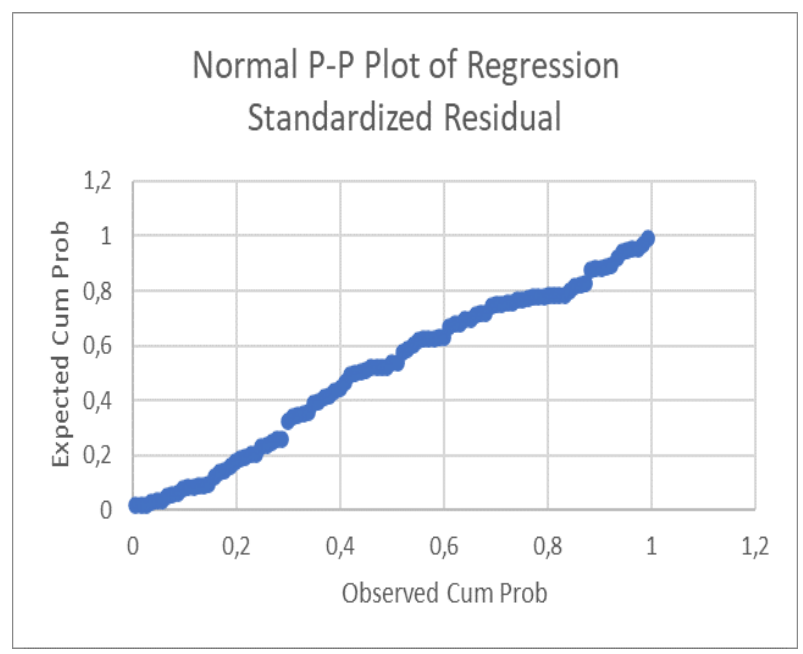

Sumber : Output SPSS yang di olah (2021)

Dapat dilihat bahwa titik menyebar secara acak dan tersebar diatas dan bibawah angka 0 , hal ini berarti tidak terjadi heteroskedastisitas pada model regresi.

Uji Regresi Linier Sederhana

Hasil Uji Regresi Linear Sederhana Variabel X Terhadap Y

\begin{tabular}{|c|c|c|c|c|c|c|}
\hline \multicolumn{7}{|c|}{ Coefficients $^{\mathrm{a}}$} \\
\hline & & \multicolumn{2}{|c|}{$\begin{array}{l}\text { Unstandardized } \\
\text { Coefficients }\end{array}$} & \multirow{2}{*}{$\begin{array}{c}\begin{array}{c}\text { Standardized } \\
\text { Coefficients }\end{array} \\
\text { Beta } \\
\end{array}$} & \multirow[b]{2}{*}{$t$} & \multirow[b]{2}{*}{ Sig. } \\
\hline \multicolumn{2}{|c|}{ Model } & $\mathrm{B}$ & Std. Error & & & \\
\hline \multirow[t]{2}{*}{1} & (Constant) & 3.018 & 1.309 & & 2.306 & 0.023 \\
\hline & $\begin{array}{l}\text { Kualitas } \\
\text { Pelayanan (X) }\end{array}$ & 0.483 & 0.036 & 0.807 & 13.469 & 0.000 \\
\hline \multicolumn{7}{|c|}{ a. Dependent Variable: Kepuasan (Y) } \\
\hline
\end{tabular}

Sumber : Output SPSS yang di olah (2021)

Diperoleh nilai siknifikansi $0,000<0,05$ dan juga nilai $t_{\text {hitung }}$ sebesar $13.469>t_{\text {tabel }}$ sebesar 1.984. maka dapat disimpulkan bahwa variabel kualitas pelayanan (X) berpengaruh terhadap variabel kepuasan masyarakat (Y). Dari tabel tersebut maka dapat diperoleh $a=3,018$ dan $b=0,483$, maka dapat dirumuskan model regresi linear sederhan sebagai berikut:

$\mathbf{Y}=\mathbf{a}+\mathbf{b X}$

$Y=3,018+0,483 X$

Berdasarkan hasil uji regresi tersebut maka dapat disipulkan konstanta 3,018 mengandung arti bahwa nilai konsisten variabel kepuasan (Y) adalah sebesar 3,018, dan koefisien regresi $\mathrm{X}$ sebesar 0,483 menunjukan bahwa setiap penambahan $1 \%$ nilai variabel kualitas pelayanan, maka nilai variabel kepuasan bertambah sebesar 0,483. 


\section{Uji Korelasi dan Determinasi}

\section{Hasil Uii Kolerasi Kualitas Pelavanan Terhadap Kepuasan}

\begin{tabular}{|c|c|c|c|}
\hline \multicolumn{4}{|c|}{ Correlations } \\
\hline & & Kualitas Pelayanan (X) & $\operatorname{Kepuasan}(\mathrm{Y})$ \\
\hline \multirow[t]{3}{*}{ Kualitas Pelayanan (X) } & $\begin{array}{l}\text { Pearson } \\
\text { Correlation }\end{array}$ & 1 & $.807^{* 4}$ \\
\hline & Sig. (2-tailed) & & 0.000 \\
\hline & $\mathrm{N}$ & 99 & 99 \\
\hline \multirow[t]{3}{*}{ Kepuasan (Y) } & $\begin{array}{l}\text { Pearson } \\
\text { Correlation }\end{array}$ & $.807^{* *}$ & 1 \\
\hline & Sig. (2-tailed) & 0.000 & \\
\hline & $\mathrm{N}$ & 99 & 99 \\
\hline
\end{tabular}

Sumber : Output SPSS yang di olah (2021)

Berdasarkan tabel 4.12 terjadi hubungan positif nilai pearson correlation $(r)$ antara $X$ dan $\mathrm{Y}$ yaitu 0,807 > 0 dapat diartikan semakin besar nilai $\mathrm{X}$ maka semakin besar juga nilai variabel $\mathrm{Y}$ dan juga sebaliknya. Hubungan antara nilai $\mathrm{X}$ dan $\mathrm{Y}$ masuk dalam kategori sangat kuat karena berada pada interval koefisien 0,80-0,100.

Berdasar tabel 4.12 , dapat diperoleh data koefisien determinasi atau $r$ square sebesar 0,652 artinya $65,2 \%$ variabel terkait yaitu Kepuasan $(\mathrm{Y})$ variasinya dapat dijelaskan oleh variabel Kualitas Pelayanan (X) dan sisanya sebesar 34,8\% dijelaskan dari luar variabel yang digunakan.

\section{Uji Hipotesis}

Hasil Uji Parsial (uji-t)

\begin{tabular}{|c|c|c|c|c|c|c|}
\hline \multicolumn{7}{|c|}{ Coefficients $^{a}$} \\
\hline & & \multicolumn{2}{|c|}{$\begin{array}{c}\text { Unstandardized } \\
\text { Coefficients }\end{array}$} & \multirow{2}{*}{$\begin{array}{c}\begin{array}{c}\text { Standardized } \\
\text { Coefficients }\end{array} \\
\text { Beta }\end{array}$} & \multirow[b]{2}{*}{$\mathrm{t}$} & \multirow[b]{2}{*}{ Sig. } \\
\hline \multicolumn{2}{|c|}{ Model } & B & Std. Error & & & \\
\hline \multirow[t]{2}{*}{1} & (Constant) & 3.018 & 1.309 & & 2.306 & 0.023 \\
\hline & $\begin{array}{l}\text { Kualitas } \\
\text { Pelayanan (X) }\end{array}$ & 0.483 & 0.036 & 0.807 & 13.469 & 0.000 \\
\hline
\end{tabular}

Sumber : Output SPSS yang di olah (2021)

Tabel 4.14 menunjukkan bahwa variabel bebas mempengaruhi variabel terikat dengan cara yang berbeda. Terlihat dari pengujian ini bahwa data variabel $\mathrm{X}$ yang diperiksa memiliki pengaruh yang signifikan terhadap variabel $\mathrm{Y}$, karena nilai signifikansi variabel $\mathrm{X}$ sebesar $0,000<0,05$. Selain itu dapat dilihat juga dari nilai t hitung sebesar 13.469 lebih besar dari nilai $t$ tabel sebesar 1.98498. Nilai t tabel diperoleh dengan melihat daftar $\mathrm{t}$ tabel dengan rumus:

$\mathrm{Df}=(\mathrm{n}-\mathrm{k}-1)$, dimana $\mathrm{n}=99$ dan $\mathrm{k}=2$

Maka dapat dihitung, $\mathrm{df}=99-2-1=96$

Maka dapat disimpukan bahwa variabel kualitas pelayanan berpengaruh positif dan signifikan terhadap kepuasan masyarakat Desa Citayam.

\section{PEMBAHASAN}

Hasil uji regresi linear sederhana menunjukan nilai konsisten variabel kepuasan (Y) sebesar 0,000 dan koefisien regresi kualitas pelayanan (X) memiliki nilai sebesar 
0,483 menunjukan bahwa setiap kualitas pelayanan mengalami peningkatan satu kali, maka nilai variabel kepuasan bertambah sebesar 0,483. Dari hasil uji koefisien kolerasi dapat dilihat hubungan antara kualitas pelayanan dan kepuasan masyarakat memiliki hubungan yang sangat kuat dengan nilai sebesar 0,807

Berdasarkan hasil penelitian ini menunjukan bahwa kepuasan konsumen dipengaruhi positif dan signifikan oleh kualitas pelayanan, dimana ditunjukan dari tariff signifikan sebesar $0,000<0,05$ dan nilai $\mathrm{t}$ hitung $>\mathrm{t}$ tabel dengan nilai sebesar $13.469>$ 1.98498. Hal ini dikarenakan semakin tinggi kualitas pelayanan maka semakin tinggi pula kepuasan masyarakat, sebaliknya semakin rendah kualitas pelayanan pada Kantor Desa maka semakin rendah pula kepuasan masyarakat Desa Citayam. Artinya jika pelayanan Kantor Desa Citayam dapat meningkatkan kemampuan dan keandalan yang terpercaya dan juga mampu memberi rasa aman serta menyediakan sarana yang membuat nyaman kepada masyarakat maka kepuasan masyarakat akan semakin tinggi.

Hasil penelitian ini mendukung hasil pengujian dari penelitian terdahulu yang sependapat bahwa terdapat pengaruh yang positif dan signifikan antara kualitas pelayanan terhadap kepuasan, dengan memberikan kualitas pelayanan yang baik maka dapat meningkatkan kepuasan.

\section{KESIMPULAN}

Berdasarkan hasil penelitian dan analisis data yang telah dilakukan kepada 99 orang yang menjadi sampel pada masyarakat Desa Citayam mengenai "Kepuasan Masyarakat di Tinjau dari Kualitas Pelayanan Yang Ada Pada Kantor Desa Citayam”, dengan rumusan masalah yang diajukan maka penulis menyimpulkan bahwa kualitas pelayanan dan kepuasan konsumen pada Kantor Desa Citayam terbilang baik, dan juga kualitas pelayanan berpengaruh signifikan dan berkontribusi positif terhadap kepuasan masyarakat.

\section{DAFTAR PUSTAKA}

Pasal 1 Undang-Undang Nomor 25 Tahun 2009

Arianto, N. (2017). Pengaruh Kualitas Pelayanan, Harga Dan Kepuasan Terhadap Loyalitas Pasien (Studi Kasus Pada Pasien Rawat Jalan Rumah Sakit Premier Bintaro). Jurnal Organisasi dan Manajemen, 13(1), 1-9.

Arianto, N. (2018). Pengaruh Kualitas Pelayanan Terhadap Kepuasan Dan Loyalitas Pengunjung Dalam Menggunakan Jasa Hotel Rizen Kedaton Bogor. Jurnal Pemasaran Kompetitif, 1(2).

Arianto, N. (2019). Pengaruh Kualitas Pelayanan Dan Promosi Terhadap Kepuasan Konsumen Pada Alfamart Roda Hias Serpong. Jurnal Ekonomi Efektif, 2(1).

Arianto, N., \& Difa, S. A. (2020). Pengaruh Kualitas Pelayanan Dan Kualitas Produk Terhadap Minat Beli Konsumen Pada PT Nirwana Gemilang Property. Jurnal Disrupsi Bisnis: Jurnal Ilmiah Prodi Manajemen, Fakultas Ekonomi, Universitas Pamulang, 3(2), 108-119.

Arianto, N., \& Kurniawan, F. (2021). Pengaruh Kualitas Pelayanan dan Promosi Terhadap Loyalitas dengan Kepuasan Sebagai Variabel Intervening (Studi Home Industri Produk Pakaian Sablon \& Bordir). Jurnal Pemasaran Kompetitif, 4(2), 254-268.

Arianto, N., \& Octavia, B. D. A. (2021). Pengaruh Kualitas Pelayanan dan Distribusi terhadap Keputusan Pembelian. Jurnal Disrupsi Bisnis, 4(2), 98-107.

Daryanto, \& Setyobudi, I. (2014). Konsumen dan pelayanan prima. Yogyakarta: Gava Media.

Kotler, Philip and Kevin Lane Keller, (2016): Marketing Management, 15th Edition New Jersey: Pearson Pretice Hall, Inc

Kotler, Philip dan Amstrong, Gary, (2012), Principles of Marketing, 15th Edition, Pearson Education Limite 